Hou, Y., Xiong, D., Jiang, T., Song, L., \& Wang, Q. (2019). Social media addiction: Its impact, mediation, and intervention. Cyberpsychology: Journal of Psychosocial Research on Cyberspace, 13(1), article 4. http://dx.doi.org/10.5817/CP2019-1-4

\title{
Social media addiction: Its impact, mediation, and intervention
}

\author{
Yubo Hou' ${ }^{1}$ Dan Xiong1, 2, Tonglin Jiang',3, Lily Song ${ }^{4}$, \& Qi Wang 5 \\ ${ }^{1}$ Peking University, China \\ ${ }^{2}$ Southwest University, China \\ ${ }^{3}$ The University of Hong Kong, Hong Kong \\ ${ }^{4}$ Institute of Psychology, Chinese Academy of Science, China \\ ${ }^{5}$ Cornell University, The USA
}

\begin{abstract}
This research examined the relations of social media addiction to college students' mental health and academic performance, investigated the role of self-esteem as a mediator for the relations, and further tested the effectiveness of an intervention in reducing social media addiction and its potential adverse outcomes. In Study 1 , we used a survey method with a sample of college students $(N=232)$ and found that social media addiction was negatively associated with the students' mental health and academic performance and that the relation between social media addiction and mental health was mediated by self-esteem. In Study 2, we developed and tested a two-stage self-help intervention program. We recruited a sample of college students $(N=38)$ who met criteria for social media addiction to receive the intervention. Results showed that the intervention was effective in reducing the students' social media addiction and improving their mental health and academic efficiency. The current studies yielded original findings that contribute to the empirical database on social media addiction and that have important theoretical and practical implications.
\end{abstract}

Keywords: Social media addiction; mental health; academic performance; self-esteem; intervention

\section{Introduction}

Human beings have fundamental needs to belong and to relate, for which interpersonal communication is the key (Baumeister \& Leary, 1995; Wang, 2013). In recent decades, with the development of information technology, especially with the rapid proliferation of Internet-based social media (e.g., Facebook, WeChat, or Instagram), the ways of interpersonal communication have drastically changed (Smith \& Anderson, 2018; Stone, \& Wang, 2018). The ubiquitous social media platforms and the easy access to the Internet bring about the potential for social media addiction, namely, the irrational and excessive use of social media to the extent that it interferes with other aspects of daily life (Griffiths, 2000, 2012). Social media addiction has been found to be associated with a host of emotional, relational, health, and performance problems (e.g., Echeburua \& de Corral, 2010; Kuss \& Griffiths, 2011; Marino, Finos, Vieno, Lenzi, \& Spada, 2017; Marino, Gini, Vieno, \& Spada, 2018). Understanding the causes, consequences, and remedies of social media addiction is thus of paramount importance. In the current research, we examined the relations of social media addiction to college students' mental health and academic performance and the role of self-esteem as a mediator for the relations (Study 1). We further tested the effectiveness of an intervention in reducing social media addiction and its potential adverse outcomes (Study 2). 


\section{Social Media Addiction and the Negative Outcomes}

Social media addiction can be viewed as one form of Internet addiction, where individuals exhibit a compulsion to use social media to excess (Griffiths, 2000; Starcevic, 2013). Individuals with social media addiction are often overly concerned about social media and are driven by an uncontrollable urge to log on to and use social media (Andreassen \& Pallesen, 2014). Studies have shown that the symptoms of social media addiction can be manifested in mood, cognition, physical and emotional reactions, and interpersonal and psychological problems (Balakrishnan \& Shamim, 2013; Błachnio, Przepiorka, Senol-Durak, Durak, \& Sherstyuk, 2017; Kuss \& Griffiths, 2011; Tang, Chen, Yang, Chung, \& Lee, 2016; Zaremohzzabieh, Samah, Omar, Bolong, \& Kamarudin, 2014). It has been reported that social media addiction affects approximately $12 \%$ of users across social networking sites (Alabi, 2012; Wolniczak et al., 2013; Wu, Cheung, Ku, \& Hung, 2013).

Many studies on social media usage and mental health have shown that the prolonged use of social media such as Facebook is positively associated with mental health problems such as stress, anxiety, and depression and negatively associated with long-term well-being (Eraslan-Capan, 2015; Hong, Huang, Lin \& Chiu, 2014; Malik \& Khan, 2015; Marino et al., 2017; Pantic, 2014; Shakya \& Christakis, 2017; Toker \& Baturay, 2016). For example, the time spent on social media was positively related to depressive symptoms among high school students in Central Serbia (Pantic et al., 2012) and among young adults in the United States (Lin et al., 2016). Furthermore, certain categories of social media use have been shown to be associated with reduced academic performance (AlMenayes, 2014, 2015; Junco, 2012; Karpinski, Kirschner, Ozer, Mellott, \& Ochwo, 2013; Kirschner \& Karpinski, 2010). For example, Lau (2017) found whereas using social media for academic purposes did not predict academic performance indexed by the cumulative grade point average, using social media for nonacademic purposes (video gaming in particular) and social media multitasking negatively predicted academic performance. A large sample $(N=1893)$ survey conducted in the United States also found that the time students spent on Facebook was negatively associated with their total GPAs (Junco, 2012). Laboratory experiments have provided further evidence for the negative relation between social media use and academic outcomes. For example, Wood et al. (2012) found that multi-tasking via texting, email, MSN, and Facebook had negative effects on real-time learning performance. Jiang, Hou, and Wang (2016) found that the use of Weibo, the Chinese equivalence of Twitter, had negative effects on information comprehension.

Importantly, frequent social media usage does not necessarily indicate social media addiction (Griffiths, 2010) and therefore does not always have negative implications for individuals' mental health (e.g., Jelenchick, Eickhoff, \& Moreno, 2013) or academic performance (Pasek \& Hargittai, 2009). A key distinction between normal overengagement in social media that may be occasionally experienced by many and social media addiction is that the latter is associated with unfavorable consequences when online social networking becomes uncontrollable and compulsive (Andreassen, 2015). Studies investigating social media addiction have mainly focused on Facebook addiction (e.g., Andreassen, Torsheim, Brunborg, \& Pallesen, 2012; Hong et al., 2014; Koc \& Gulyagci, 2013). It has been shown that addiction to Facebook is positively associated with depression, anxiety, and insomnia (Bányai et al., 2017; Koc \& Gulyagci, 2013; Shensa et al., 2017; van Rooij, Ferguson, van de Mheen, \& Schoenmakers, 2017) and negatively associated with subjective well-being, subjective vigor, and life satisfaction (Błachnio, Przepiorka, \& Pantic, 2016; Hawi \& Samaha, 2017; Uysal, Satici, \& Akin, 2013). Research has also suggested the negative impact of social media addiction, and Facebook addiction in particular, on academic performance (Huang, 2014; Nida, 2018).

\section{The Role of Self-Esteem}

One factor that may underlie the negative effects of social media addiction is self-esteem. Although viewing or editing one's own online profile enhances self-esteem, according to the Hyperpersonal Model (Gonzales \& Hancock, 2010), social media users are frequently exposed to others' selective and glorified online selfpresentations, which can, in turn, reduce the viewers' self-esteem (Rosenberg \& Egbert, 2011). For example, frequent Facebook users believe that others are happier and more successful than themselves, especially when they do not know well the other users offline (Chou \& Edge, 2012). Vogel, Rose, Roberts, and Eckles (2014) suggest that the extent of upward social comparisons on Facebook is greater than the extent of downward social comparisons and that upward social comparisons on social media may diminish self-esteem. Empirical studies have provided support to this proposal. For example, a study by Mehdizadeh (2010) showed that the use of 
Facebook was correlated with reduced self-esteem, such that individuals who spent a greater amount of time on Facebook per session and who made a greater number of Facebook logins per day had lower self-esteem. Another study found that adolescents' self-esteem was lowered after receiving negative feedback on social media (Valkenburg, Peter, \& Schouten, 2006). Moreover, recent studies have revealed a negative relation between addictive use of social media and self-esteem (e.g., Andreassen, Pallesen, \& Griffiths, 2017; Błachnio, et al., 2016).

A considerable number of studies have shown that low self-esteem is associated with many psychological dysfunctions such as depression and anxiety (e.g., Orth, Robins, \& Roberts, 2008; Orth \& Robins, 2013; Sowislo \& Orth, 2013). Self-esteem has also been shown to be positively associated with academic performance (e.g., Lane, Lane, \& Kyprianou, 2004; Lent, Brown, \& Larkin, 1986) and further serve as a protective factor against adversities in aiding academic and emotional resilience (Raskauskas, Rubiano, Offen, \& Wayland, 2015). It is possible that social media addiction contributes to lower self-esteem, which, in turn, leads to a decrease in mental health and academic performance. In other words, self-esteem may play a mediating role in the relations of social media addiction to mental health and academic performance.

\section{The Present Study}

To further examine the relations of social media addictions to individuals' mental health and academic performance, we conducted two studies. In Study 1, we investigated the relations of social media addictions to mental health and academic performance in college students and examined the role of self-esteem as a potential mediator for the relations. A survey method was used in which participants reported their addiction to social media, as well as their mental health, academic performance, and self-esteem. Built on the findings of Study 1, we designed an experimental intervention in Study 2 to reduce social media addiction and further promote college students' mental health and academic performance.

In both studies, we used the Bergen Social Media Addiction Scale (BSMAS; Andreassen et al., 2017) to measure social media addiction. Based on the general addiction theory, Andreassen and colleagues (2012) first developed the Bergen Facebook Addiction Scale (BFAS), with six items each describing one dimension of addictive behavior (i.e., salience, mood modification, tolerance, withdrawal symptoms, conflict, and relapse). The scale has good psychometric properties, and the addiction can be scored using a polythetic scoring scheme (i.e., scoring 3 or above on at least four of the six items) or a monothetic scoring scheme (i.e., scoring 3 or above on all six items) (Andreassen et al., 2012). One critique of BFAS is that it is specific to Facebook addiction and thus may not be appropriate for examining addiction to online social networking more generally (Griffiths, 2012). Andreassen and colleagues (2017) later revised BFAS into BSMAS, replacing "Facebook" with "social media." It has been shown to have excellent reliability (Cronbach's alpha $=.88$ ) for measuring social media addiction. In addition, BSMAS has been used with non-English populations such as Iranian, Italian, and Hong Kong samples and demonstrated robust psychometric properties (Lin, Broström, Nilsen, Griffiths, \& Pakpour, 2017; Monacis, De Palo, Griffiths, \& Sinatra, 2017; Yam et al., 2018).

Based on the findings of previous studies (e.g., Jiang et al., 2016; Koc \& Gulyagci, 2013; Pantic et al., 2012; Valkenburg et al., 2006), we hypothesized that social media addiction would be negatively associated with college students' mental health and academic performance, and that these relations would be mediated by the students' self-esteem. We further expected that an intervention to reduce social media addiction would alleviate its negative associations with mental health and academic performance.

\section{Study 1}

Study 1 utilized a survey method to investigate the relations of social media addiction to mental health and academic performance in college students and to examine the role of self-esteem as a potential mediator for the relations.

\section{Method}

Participants. The participants were undergraduate students recruited through a social psychology course at Peking University, China. A total of 250 students who enrolled in the course participated in the study for one course 
credit. Among the students, 18 did not complete the questionnaires and were excluded. The final sample thus included 232 participants (117 males, 115 females; Mean $_{\text {age }}=19.18$ years, $S D_{\text {age }}=1.32$ ).

Procedure and materials. Participants each completed a set of questionnaires in class. They were told that the questionnaires were unrelated to each other and that they should carefully answer all questions.

Social media addiction. The 6-item Bergen Social Media Addiction Scale (BSMAS; Andreassen et al., 2017) was used to measure the participants' addictive use of social media. The items concern experiences occurring over the past year and are rated on 5-point scales ranging from 1 (Very rarely) to 5 (Very often) (e.g., "How often during the last year have you felt an urge to use social media more and more?"). Given the characteristics of social networking sites in mainland China, we replaced the examples of social media sites in the original scale, namely "Facebook, Twitter, Instagram and the like," with those popular in China, "QQ, Weibo, WeChat and the like" in the instruction. A bilingual researcher translated the scale into Chinese, which was then back translated into English by another researcher. The original English version was compared with the back-translated version to resolve any discrepancies between them. The Cronbach's alpha of the Chinese version in the current sample was 0.81 . Participants' ratings were summed across the 6 items to form a social media addiction score, with higher scores indicating greater social media addiction.

Mental health. Mental health was measured by a 20-item questionnaire adapted by Li and Kam (2002) from the 30-item General Health Questionnaire (GHQ-30; Goldberg, 1972). This questionnaire includes three sub-scales: depression (Cronbach's $\alpha=.65$ ), anxiety (Cronbach's $\alpha=.73$ ), and sense of adequacy (Cronbach's $\alpha=.63$ ). Participants were asked to answer "Yes" or "No" about their feelings in recent weeks (e.g., "I feel that being alive has no meaning," "I feel unsettled or nervous all day long," and "I go happily through daily life"). The scores for depression and anxiety were reverse-coded. Scores of the three sub-scales were then summed (Cronbach's $a=.80$ ), with higher scores indicating better mental health.

Academic performance. Given that the participants came from diverse majors and different classes, their academic performance was measured by self-reported ranking relative to their respective peers. Participants were asked to rank their academic performance relative to their peers in the past semester as 1) $20 \%$ or below; 2 ) 20 $40 \%$; 3) 40 - 60\%; 4) 60 - 80\%; or 5) $80-100 \%$.

Self-esteem. The 10-item Chinese version of the Self-esteem Scale (Cronbach's a = .82; Ji \& Yu, 1993) adapted from Rosenberg (1965) was used to measure self-esteem (e.g., "I feel that I have a number of good qualities"). Participants answered the questions on 4-point scales ranging from 1 (strongly disagree) to 4 (strongly agree). Higher scores indicated higher levels of self-esteem.

At last, participants were asked to report demographic information including age, gender, only child or non-only child status, and urban or rural residence, and they were fully debriefed and thanked.

\section{Results and Discussion}

In the current sample, $41.4 \%$ of the participants scored 3 or above on at least four of the six items (the polythetic scoring scheme of BSMAS), and $9.9 \%$ scored 3 or above on all six items (the monothetic scoring scheme of BSMAS; Andreassen et al., 2012). Also, $14.7 \%$ of the participants could be classified as having social media addiction, whose composite score was above 18 and who scored 3 or above on at least four of the six items. This percentage was close to what was previously reported (12\%) in a Chinese sample (Wu et al., 2013). Participants who were only children had poorer academic performance, $t(194)=2.71, p=.007, d=.44$, higher levels of self-esteem, $t(228)=$ $2.44, p=.02, d=.38$, and lower social media addiction scores, $t(228)=-2.58, p=.01, d=-.40$, than did those with siblings. Participants who came from cities had higher levels of self-esteem, $t(214)=2.87, p=.005, d=.57$, than did those from rural areas. Gender and age were not significantly correlated with any variables.

Following previous studies (Andreassen et al., 2012, 2017; Koc \& Gulyagci, 2013; Hong et al., 2014), we treated the social media addiction score as a continuous variable to examine the degree of additive use of social media in relation to mental health and academic performance. Table1 presents the means and standard deviations (SDs) of key variables and the correlations among them. Social media addiction was negatively correlated with mental 
health, whereby the higher one scored on social media addiction, the poorer mental health he or she had. Social media addiction was also negatively correlated with academic performance as well as self-esteem. Self-esteem, on the other hand, was positively related to mental health. Mental health and academic performance were also positively correlated.

Table 1. Means, SDs and Correlations among Study Variables.

\begin{tabular}{llllll}
\hline & $\mathbf{M}$ & SD & $\mathbf{1}$ & $\mathbf{2}$ & $\mathbf{3}$ \\
\hline 1 Social media addiction & 14.77 & 4.13 & & & \\
2 Self-esteem & 29.10 & 4.19 & $-.23^{* * *}$ & & \\
3 Mental health & 14.28 & 3.91 & $-.29^{* * *}$ & $.55^{* *}$ & \\
4 Academic performance & 3.26 & 1.15 & $-.16^{*}$ & .13 & $.20^{*}$ \\
\hline
\end{tabular}

Note: ${ }^{*} p<.05,{ }^{* *} p<.01,{ }^{* * *} p<.001$

We further conducted partial correlation analyses among the key variables, controlling for demographic variables (i.e., age, gender, only child status, and residence). The pattern of results remained identical. The partial correlations between social media addiction and mental health, academic performance, and self-esteem remained significant, $r \mathrm{~s}(232)=-.29(p<.001),-.15(p=.048)$, and $-.20(p=.007)$, respectively. Self-esteem and mental health were also significantly correlated, $r(232)=.55, p<.001$, so were mental health and academic performance, $r(232)=.20, p=.007$.

Because self-esteem was not correlated with academic performance, the mediation effect was not tested further for academic performance. To test whether self-esteem played a mediating role in the relations of social media addiction to mental health, we conducted three steps of regression analyses (Wen, Hou, \& Zhang, 2005). In the first step, we regressed mental health on demographic variables and social media addiction. Social media addiction uniquely predicted mental health, $\beta=-.29, t(210)=-4.28, p<.001$. In the second step, we regressed selfesteem on demographic variables and social media addiction. Social media addiction uniquely predicted selfesteem. $\beta=-.19, t(210)=-2.75, p=.007$. In the third step, demographic variables were entered in the first layer, social media addiction was entered in the second layer, and self-esteem was entered in the third layer to predict mental health. After self-esteem was entered, the size of the standard regression coefficient of social media addiction decreased from -.29 to $-.19, t(209)=-3.26, p=.001, \Delta R^{2}=.26, p<.001$. Thus, the relation between social media addiction and mental health was at least partially mediated by self-esteem. The mediating effect of selfesteem is shown in Figure 1.

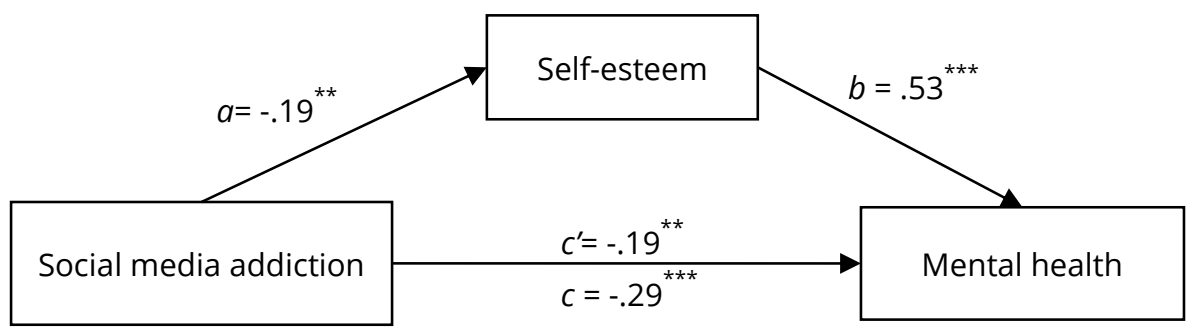

Figure 1. Mediating effect of self-esteem (Study 1 ). ${ }^{* *} p<.01, p^{* * *}<.001$.

To corroborate the findings, we further tested the mediating effect of self-esteem using a bootstrapping analysis with 5,000 iterations (Preacher \& Hayes, 2008). The 95\% confidence interval was [-.1807, -.0215], excluding 0, which indicates that the mediating effect of self-esteem was significant. To explore an alternative pathway, we tested the mediating effect of self-esteem with social media addiction as the dependent variable and mental health as the independent variable. The 95\% confidence interval was $[-.1422, .0844]$, including 0 , indicating that the reverse mediating effect of self-esteem was not significant. Thus, the results support our hypothesis that social media addiction was associated with reduced mental health through lowering individuals' self-esteem. 
Results from Study 1 confirmed our hypotheses that social media addiction was negatively associated with mental health, consistent with findings from previous studies (e.g., Koc \& Gulyagci, 2013). Furthermore, as expected, we found that self-esteem played a mediating role in the relation between social media addiction and mental health, and that the reverse mediating effect was not significant. These findings suggest that the negative association between social media addiction and mental health is at least partially accounted for by reduced self-esteem.

In addition, results from Study 1 also confirmed our prediction that social media addiction was negatively related to academic performance, although the relation was not strong. On the other hand, self-esteem was not significantly associated with academic performance, which differed from previous studies (Lane et al., 2004; Lent et al., 1986; Raskauskas et al., 2015). This might be because there was only one self-report item to measure academic performance, which could be vulnerable to the influence of social desirability concerns. In addition, given that we did not measure the time participants spent on social media, it is unclear how social media use may differ from social media addiction in relation to mental health and academic performance. We addressed these limitations in Study 2.

\section{Study 2}

Study 1 showed that the addictive use of social media was common among college students and that it was negatively associated with mental health and academic performance. One important follow-up question is whether social media addiction can be reduced and thus its negative associations with health and academic outcomes be alleviated. No study that we know of has considered intervention options for social media addiction. We therefore designed an intervention program for social media addiction based on Young's (1999) recommendations for the treatment of Internet addiction, and we conducted an experiment to verify its effectiveness.

To design an intervention program for social media addiction, we referred to previous studies on Internet addiction interventions. Research has shown that metacognitive beliefs about one's thinking and self-regulation influence problematic Internet use and social media addiction (Casale, Rugai, \& Fioravanti, 2018; Caselli et al., 2018; Spada, Langston, Nikćević, \& Moneta, 2008). According to the cognitive-behavioral model, cognitive distortions such as the ruminative cognitive style are the primary cause of excessive Internet use (Davis, 2001). These cognitive distortions can be automatically activated whenever there is a stimulus associated with the Internet. A vicious cycle of cognitive distortions and reinforcement then results in negative outcomes. This model has been widely used in addiction research related to pathological Internet overuse (LaRose, Lin, \& Eastin, 2003; Liu \& Peng, 2009; Turel, Serenko, \& Giles, 2011). A number of cognitive-behavioral therapy techniques have been recommended for treating Internet addiction (Young, 2007; Gupta, Arora, \& Gupta, 2013). Based on this literature, we believe that the cognitive-behavioral approach will be a helpful way to mitigate the negative associations of social media addiction with health and academic outcomes. It will help individuals with social media addiction to recognize their cognitive distortions and further guide them to reconstruct their thinking and behavior.

In Study 2, we combined cognitive reconstruction, reminder cards, and the diary technique (Young, 1999) into a novel intervention program and designed a 2 by 2 mixed-model experiment to test its effectiveness. In line with findings of previous studies on Internet addiction (e.g., Gupta et al., 2013; Turel et al., 2011; Young, 2007), we predicted that compared with a control group, the experimental group who experienced the intervention would show reduced social media addiction and improved outcomes in mental health and academic efficiency. We included measures of multiple outcome variables to achieve more reliable results, including daily social media use time, self-esteem, sleep quality, mental health, emotional state, learning time, and learning engagement.

\section{Method}

Participants. Study 2 was conducted at Peking University, China. Participants who exhibited social media addiction were preselected from a pool of 242 undergraduate students who enrolled in a social psychology course (a different pool from Study 1). The students were asked to complete the 6-item BSMAS (Andreassen et al.,2017). Among them, 43 students scored higher than 18 on the composite score and also scored 3 or above on at least four of the six items. These students were selected to participate in Study 2. They were randomly assigned to either an experimental or a control group and were tested both before (Time 1) and after the intervention (Time 
2). The study was thus a $2 \times 2$ mixed-model design. The 21 participants in the experimental group completed all aspects of the intervention and both tests. Five of the 22 participants in the control group dropped out before the completion. Hence, the final sample included 38 participants (18 males, 18 females, two unreported; $M_{\text {age }}=19.71$, $\left.S D_{\text {age }}=1.43\right)$.

Procedures and measures. The intervention program was approved by the Research Ethics Committee of the School of Psychological and Cognitive Sciences at Peking University. Prior to the intervention at Time 1, all participants were informed that the purpose of this study was to investigate social media addiction and they were asked to provide informed consent. Participants then completed a survey, which included the measures of social media addiction, self-esteem, and mental health, same as in Study 1. In addition, participants were asked to report their daily social media use time, indicating the number of hours they spent on social media per day. Participants also reported their sleep quality, rating on a 5-point scale ranging from 1 (very bad) to 5 (very good).

Participants in the experimental group then participated in a one-week intervention program, while those in the control group did not receive any instruction during this time. The intervention included two stages. The first stage involved cognitive reconstruction and took approximately 30 minutes (Young, 1999). Participants visited the lab, where they were asked to reflect on their social media use from five respects: How much time they spent on social media per day and per week? What other meaningful things they could do with that time? What were the benefits of not using social media? Why did they use social media and were there alternative way to achieve the purposes? What were the adverse effects of social media use? Participants wrote down their responses. After the reflection, participants were asked to each list on a card five advantages of reducing the use of social media and five disadvantages of excessive use of social media. They were then asked to take a photo of the card and use it as a lock screen of their phones that would serve as a reminder for themselves. They were also instructed to post the card on their desks during the following week.

The second stage of the intervention took place in the following week, during which participants in the experimental group were asked to keep a daily to record their thoughts, emotions, and behaviors related to social media use, as part of the cognitive-behavioral techniques (Young, 1999). Participants reflected on their daily use of social media every night before going to bed, including what social media they used, how long and how they used the social media, their thoughts and emotions related to their social media use, and the strategies they would like to use to reduce social media use. They were also asked to indicate their emotional state and learning engagement, as well as their expected social media use the next day. To ensure that the participants followed the instruction, daily reminders were sent to them to complete the recording. Participants were further instructed to take a photo of their completed recording and send it to a contact researcher of the lab to confirm its completion. The participants' responses in the daily reflection task were part of the intervention and were not used in analysis.

After the intervention, at Time 2, all participants completed another survey. The measures included social media addiction, daily social media use time, self-esteem, sleep quality, and mental health, same as those at Time 1. In addition, the participants' learning engagement in the past week was measured by the 17-item Utrecht Work Engagement Scale-Student (UWES-S, Fang, Shi, \& Zhang, 2008). Participants answered the questions (e.g., "My study inspires me") on 5-point scales ranging from 1 (strongly disagree) to 5 (strongly agree) (Cronbach's $a=0.93$ for the current sample). A total score was summed, with higher scores indicating higher levels of learning engagement. Participants also reported their daily learning time outside the class in the past week and rated on their emotional state in the past week on a scale ranging from 1 (very bad) to 100 (very good).

Finally, participants in the experimental group provided feedback on the effectiveness of the intervention. They answered 7 questions concerning the various aspects of the intervention (e.g., "Generally, I think the intervention is effective") on 5-point scales from 1 (strongly disagree) to 5 (strongly agree) (Cronbach's $\alpha=0.81$ ). At last, participants were fully debriefed and thanked.

\section{Results and Discussion}

Across all dependent variables, 2 (Group: Experimental vs. Control) x 2 (Test time: Time 1 vs. Time 2) mixed-model analyses were conducted to examine the effect of intervention. First, the analysis on social media addiction score revealed main effects of group, $F(1,36)=7.89, p=.008, \eta_{p}{ }^{2}=.18$, and test time, $F(1,36)=33.74, p<.001, \eta_{p}{ }^{2}=.48$, 
qualified by a significant interaction, $F(1,36)=17.92, p<.001, \eta_{p}{ }^{2}=.33$. For participants in the experimental group, there was a significant decrease in social media addiction from Time 1 to Time 2, changing from 20.62 (higher than 18) to 14.62 (lower than 18 ), $t(20)=7.17, p<.001, d=1.97$. In contrast, for participants in the control group, there was no significant change in their social media addiction, $t(16)=1.13, p=.28, d=.35$. Figure 2 illustrates the interaction effect.

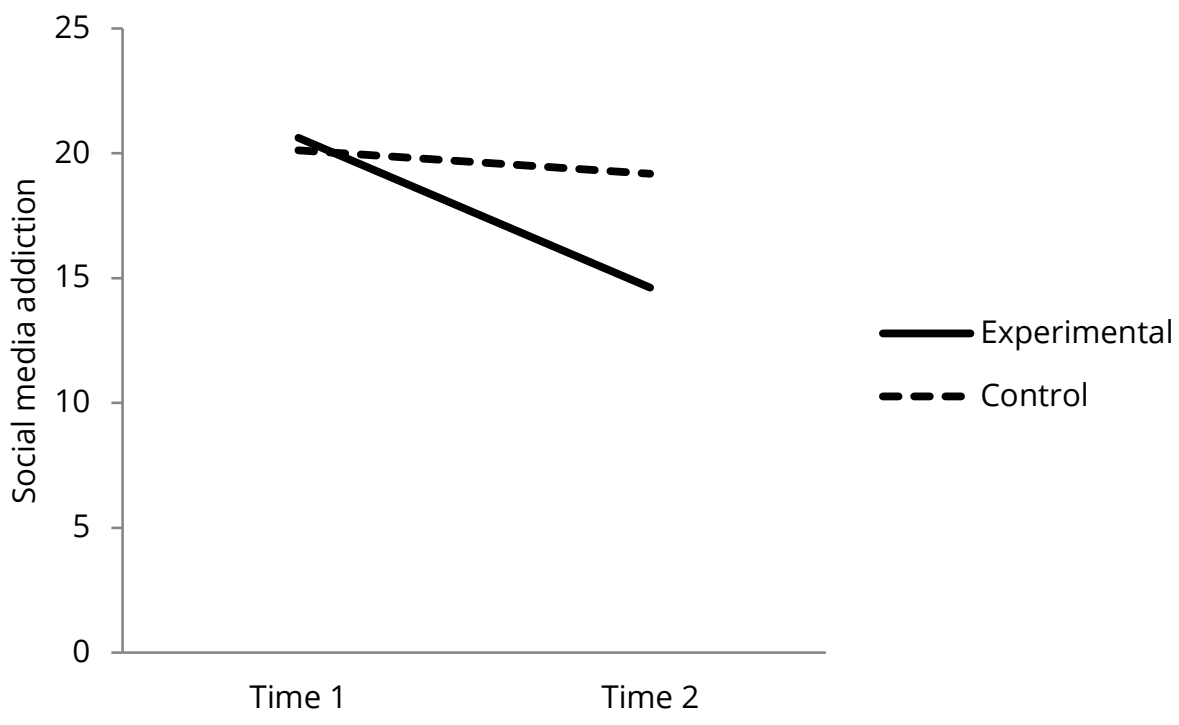

Figure 2. Social media addiction as a function of test time and group (Study 2).

The same analysis was conducted to examine the effect of intervention on daily social media use time, self-esteem, sleep quality, and mental health, respectively. Table 2 presents means and standard deviations for all variables and t-tests within each group. For daily social media use time, there was a main effect of test time, $F(1,36)=26.54$, $p<.001, \eta_{p}{ }^{2}=.42$, qualified by a Group x Test time interaction, $F(1,36)=10.47, p=.003, \eta_{p}^{2}=.23$. Further t-tests within each group showed that whereas the average daily time participants spent on social media was reduced significantly from Time 1 to Time 2 for both groups, the reduction was larger for the experimental group. There was only a main effect of test time for self-esteem, $F(1,36)=12.67, p=.001, \eta_{p}{ }^{2}=.26$, and sleep quality, $F(1,36)=$ $9.10, p=.005, \eta_{p}^{2}=.20$, whereby self-esteem and sleep quality increased from Time 1 to Time 2 . However, further t-tests within each group showed that the improvements were only significant for the experimental group, but not the control group. For mental health, a significant Group $x$ Test time interaction emerged, $F(1,36)=5.69, p=.02$, $\eta_{p}{ }^{2}=.14$. Whereas mental health scores increased from Time 1 to Time 2 for the experimental group, $t(20)=2.55$, $p=.02, d=.59$, there was no change for the control group, $t(16)=-.86, p=.40, d=-.19$. Taken together, these results suggest that our intervention effectively reduced social media addiction and improved mental health and other outcomes.

Further analyses of the remaining outcome variables at Time 2 showed that compared with the control group, participants in the experimental group exhibited better learning engagement, $t(36)=.2 .31, p=.03, d=.77$, spent more time on their study outside the class, $t(36)=2.28, p=.03, d=.75$, and experienced a better emotional state, $t(36)=2.74, p=.01, d=.86$, during the intervention period. In addition, participants in the experimental group reported that the intervention was effective: all participants rated over 3 for the overall intervention; $81 \%$ rated over 3 for the first stage of the intervention and $90 \%$ for the second. All participants reported that the daily reflections were helpful, and $86 \%$ of them were willing to continue to participate in similar studies. 
Table 2. Mean and standard deviation of Time 1andTime2's test scores of key variables

\begin{tabular}{|c|c|c|c|c|c|c|c|}
\hline \multirow{2}{*}{ Outcome variables } & \multirow{2}{*}{ Group(n) } & \multicolumn{2}{|l|}{ Time 1} & \multicolumn{2}{|c|}{ Time 2} & \multirow[b]{2}{*}{ t } & \multirow{2}{*}{$\mathbf{p}$} \\
\hline & & M & SD & M & SD & & \\
\hline \multirow[t]{2}{*}{ Social media addiction } & Experimental(21) & 20.62 & 2.16 & 14.62 & 3.72 & 7.17 & $<.001 * \star \star$ \\
\hline & Control(17) & 20.12 & 2.15 & 19.18 & 3.07 & 1.13 & .275 \\
\hline \multirow{2}{*}{$\begin{array}{l}\text { Daily social media use } \\
\text { time }\end{array}$} & Experimental(21) & 4.65 & 2.67 & 1.56 & .98 & 5.09 & $<.001 * * *$ \\
\hline & Control(17) & 3.85 & 2.31 & 3.15 & 1.48 & 2.16 & $.046 *$ \\
\hline \multirow[t]{2}{*}{ Self-esteem } & Experimental(21) & 28.67 & 3.68 & 30.67 & 3.17 & -3.87 & $.001 * \star$ \\
\hline & Control(17) & 27.41 & 3.18 & 28.35 & 3.81 & -1.42 & .174 \\
\hline \multirow[t]{2}{*}{ Sleep quality } & Experimental(21) & 3.38 & .86 & 3.95 & .86 & -3.51 & $.002 * \star$ \\
\hline & Control(17) & 3.35 & 1.00 & 3.59 & .80 & -1.07 & .299 \\
\hline \multirow[t]{2}{*}{ Mental health } & Experimental(21) & 13.24 & 4.45 & 15.71 & 3.89 & -2.55 & $.019 *$ \\
\hline & Control(17) & 13.18 & 4.07 & 12.35 & 4.58 & .86 & .403 \\
\hline
\end{tabular}

In sum, participants in the experimental group exhibited reduced social media addiction and improved mental health as well as self-esteem and sleep quality after a two-stage intervention, whereas there was no significant change in the control group. The experimental group participants evaluated the intervention to be effective, in line with prior research showing that cognitive reconstruction, the reminder card technique, and daily reflections are effective methods in reducing Internet addiction (Young, 1999). Furthermore, compared with those in the control group, participants who received the intervention spent more time on learning and experienced a higher level of learning engagement and better emotional state. It is noteworthy that although control group participants reported reduced social media use time at Time 2, they did not exhibit reduced social media addiction or significant improvement in any outcome measures. This is consistent with the theoretical notion that the mere social media use time is not equivalent with or sufficient to index social media addiction (Griffiths, 2010; Andreassen, 2015). Together, these findings suggest that our intervention was effective in reducing social media addiction and improving college students' mental health and learning efficiency.

\section{General Discussion}

The current studies provided empirical support that social media addiction was negatively associated with college students' mental health and academic performance (Pantic et al., 2012; Jelenchick et al., 2013). Furthermore, in line with previous findings that social media addiction negatively affects self-esteem (Andreassen et al., 2017; Błachnio, et al., 2016; Chou \& Edge, 2012; Vogel et al., 2014) and that low self-esteem is associated with mental disorders (Orth et al., 2008; Orth \& Robins, 2013; Sowislo \& Orth, 2013), the current research yielded the first empirical finding that self-esteem mediated the relation of social media addiction to mental health. Furthermore, the implementation of an intervention based on the cognitive-behavioral approach (Young, 1999, 2007; Gupta et al., 2013) effectively reduced social media addiction and improved mental health and academic efficiency.

Notably, our results showed that social media addiction was associated with reduced mental health partly through lowering individuals' self-esteem, and that the reverse mediating effect of self-esteem with mental health as the predictor and social media addiction as the outcome variable was not significant. Nevertheless, it does not rule out the possibility that poor mental health can further contribute to social media addiction. Individuals in poor mental health, including those with low self-worth, may use social media as a compensation for their real-life interpersonal deficiency and further develop excessive dependence on social media (Zywica \& Danowski, 2008). Also, individuals in poor mental health often try to use social media to improve their mood and, when this need is not met, their mental condition tends to become worse (Caplan, 2010). Thus, the relation between poor mental health and social media addiction is likely to be bidirectional.

The present studies provided strong support for the relation of social media addiction to academic outcomes by using a variety of measures. Study 1 showed that a self-rank measure of academic performance was negatively associated with social media addiction. This relation was not mediated by self-esteem. Study 2 further showed 
that an intervention to reduce social media addiction improved learning engagement and increased the time spent on learning outside the class. We speculate that there may be three explanations for the negative relation of social media addiction to academic performance. First, social media addiction may mean more time spent online and less time spent on study. Excessive social media use interrupts students' time management, which further affects academic performance (Macan, Shahani, Dipboye, \& Phillips, 1990). Second, social media addiction may interfere with students' work by distracting them and making them unable to stay focused. Research has shown that multitasking has negative effects on the performance of specific tasks (Ophir, Nass, \& Wagner, 2009). Finally, given that students with social media addiction may be easily distracted, it can be difficult for them to encode and remember what they are learning (Oulasvirta \& Saariluoma, 2006).

Our intervention program effectively reduced social media addiction and improved students' mental health and learning efficiency. This has important practical implications by showing that social media addiction can be mitigated through cognitive reconstruction and the supporting techniques. The stage of cognitive reconstruction helped students realize the negative consequences of their addiction to social media as well as the potential benefits of reducing social media usage. The subsequent application of the reminder card as a lock screen of their phones as well as the daily reflections further reinforced this awareness. These findings suggest that helping college students to gain a better understanding of the adverse effects of social media addiction through costefficient self-help interventions can reduce social media addiction and have the potential to improve mental health and academic performance.

The current studies have some limitations. First, participants were recruited through psychology courses at Peking University and the sample sizes were relatively small especially in Study 2, which may limit the generalizability of the findings. Future studies should include more diverse and larger samples to increase external validity. Second, participants in the control group of Study 2 did not receive any instruction during the one-week interval and they could be distracted by things unrelated to the study. Future research should establish more strict control conditions to eliminate any confounding variables. Third, the intervention in Study 2 was limited in length and the post-treatment data were collected only once, right after the intervention ended. It is therefore unclear whether the intervention effects on social media addiction and other outcomes would persist over time. Given that the current intervention program for reducing social media addiction was newly developed, it requires further refinement to improve its effectiveness. In addition, future studies should investigate the bidirectional relation between social media addiction and mental health, using longitudinal approaches to further validate the mediating role of self-esteem and examine other potential mediators such as cognitive distortions for the relations of social media addiction to mental health and other outcomes.

In conclusion, the current research revealed negative associations between social media addiction and college students' mental health and academic performance, and the role of self-esteem as an underlying mechanism for the relation between social media addiction and mental health. A cost-efficient intervention that included cognitive reconstruction, reminder cards, and a week-long diary keeping effectively reduced the addiction to social media and further improved mental health and academic efficiency.

\section{Acknowledgements}

This research was supported by grants from the Chinese National Natural Science Foundation (31371053, 31528014) to Qi Wang and Yubo Hou.

\section{References}

Al-Menayes, J. J. (2014). The relationship between mobile social media use and academic performance in university students. New Media and Mass Communication, 25, 23-29.

Al-Menayes, J. J. (2015). Social media use, engagement and addiction as predictors of academic performance. International Journal of Psychological Studies, 7, 86-94. http://dx.doi.org/10.5539/ijps.v7n4p86

Alabi, O. F. (2012). A survey of Facebook addiction level among selected Nigerian University undergraduates. New Media and Mass Communication, 10, 70-80. 
Andreassen, C. S. (2015). Online social network site addiction: A comprehensive review. Current Addiction Reports, 2, 175-184. https://doi.org/10.1007/s40429-015-0056-9

Andreassen, C. S., \& Pallesen, S. (2014). Social network site addiction-an overview. Current Pharmaceutical Design, 20, 4053-4061. https://doi.org/10.2174/13816128113199990616

Andreassen, C. S., Pallesen, S., \& Griffiths, M. D. (2017). The relationship between addictive use of social media, narcissism, and self-esteem: Findings from a large national survey. Addictive Behaviors, 64, 287-293.

https://doi.org/10.1016/j.addbeh.2016.03.006

Andreassen, C. S., Torsheim, T., Brunborg, G. S., \& Pallesen, S. (2012). Development of a Facebook addiction scale. Psychological Reports, 110, 501-517. https://doi.org/10.2466/02.09.18.PR0.110.2.501-517

Balakrishnan, V., \& Shamim, A. (2013). Malaysian Facebookers: Motives and addictive behaviours unraveled. Computers in Human Behavior, 29, 1342-1349. https://doi.org/10.1016/j.chb.2013.01.010

Bányai, F., Zsila, Á., Király, O., Maraz, A., Elekes, Z., Griffiths, M. D., .. Demetrovics, Z. (2017). Problematic social media use: Results from a large-scale nationally representative adolescent sample. PLoS One, 12, e0169839. https://doi.org/10.1371/journal.pone.0169839

Baumeister, R. F., \& Leary, M. R. (1995). The need to belong: Desire for interpersonal attachment as a human motivation. Psychological Bulletin, 117, 497-529. https://doi.org/10.1037 /0033-2909.117.3.497

Błachnio, A., Przepiorka, A., \& Pantic, I. (2016). Association between Facebook addiction, self-esteem and life satisfaction: A cross-sectional study. Computers in Human Behavior, 55, 701-705.

https://doi.org/10.1016/j.chb.2015.10.026

Błachnio, A., Przepiorka, A., Senol-Durak, E., Durak, M., \& Sherstyuk, L. (2017). The role of personality traits in Facebook and Internet addictions: A study on Polish, Turkish, and Ukrainian samples. Computers in Human Behavior, 68, 269-275. https://doi.org/10.1016/j.chb.2016.11.037

Caplan, S. E. (2010). Theory and measurement of generalized problematic Internet use: A two-step approach. Computers in Human Behavior, 26, 1089-1097. https://doi.org/10.1016/j.chb.2010.03.012

Casale, S., Rugai, L., \& Fioravanti, G. (2018). Exploring the role of positive metacognitions in explaining the association between the fear of missing out and social media addiction. Addictive Behaviors, 85, 83-87. https://doi.org/10.1016/j.addbeh.2018.05.020

Caselli, G., Fernie, B., Canfora, F., Mascolo, C., Ferrari, A., Antonioni, M., Spada, M. M. (2018). The metacognitions about gambling questionnaire: Development and psychometric properties. Psychiatry Research, 261, 367-374. https://doi.org/10.1016/j.psychres .2018.01.018

Chou, H. T. G., \& Edge, N. (2012). "They are happier and having better lives than I am": The impact of using Facebook on perceptions of others' lives. Cyberpsychology, Behavior, and Social Networking, 15, 117-121. https://doi.org/10.1089/cyber.2011.0324

Davis, R. A. (2001). A cognitive-behavioral model of pathological Internet use. Computers in Human Behavior, 17, 187-195. https://doi.org/10.1016/S0747-5632(00)00041-8

Echeburua, E., \& de Corral, P. (2010). Addiction to new technologies and to online social networking in young people: A new challenge. Adicciones, 22, 91-95. https://doi.org/10.1016/j.addbeh.2009.09.003

Eraslan-Capan, B. (2015). Interpersonal sensitivity and problematic Facebook use in Turkish university students. The Anthropologist, 21, 395-403. https://doi.org/10.1080/09720073.2015.11891829 
Fang, L. T., Shi, K., \& Zhang, F. H. (2008). Research on reliability and validity of Utrecht Work Engagement Scalestudent. Chinese Journal of Clinical Psychology, 16, 618-620. https://doi.org/1005-

3611(2008)16:6<618:ZWBXXT>2.0.TX;2-X

Goldberg, D. P. (1972). The detection of psychiatric illness by questionnaire: A technique for the identification and assessment of nonpsychotic psychiatric illness. London: Oxford University Press.

Gonzales, A. L., \& Hancock, J. T. (2011). Mirror, mirror on my Facebook wall: Effects of exposure to Facebook on self-esteem. Cyberpsychology, Behavior, and Social Networking, 14, 79-83. https://doi.org/10.1089/cyber.2009.0411

Griffiths, M. D. (2000). Internet addiction: Time to be taken seriously? Addiction Research, 8, 413-418.

https://doi.org/10.3109/16066350009005587

Griffiths, M. D. (2010). The role of context in online gaming excess and addiction: Some case study evidence. International Journal of Mental Health and Addiction, 8, 119-125. https://doi.org/10.1007/s11469-009-9229-x

Griffiths, M. D. (2012). Facebook addiction: Concerns, criticism, and recommendations: A response to Andreassen and colleagues. Psychological Reports, 110, 518-520. https://doi.org/10.2466/01.07.18.PR0.110.2.518520

Gupta, V. K., Arora, S., \& Gupta, M. (2013). Computer-related illnesses and Facebook syndrome: What are they and how do we tackle them. Medicine Update, 23, 676-679.

Hawi, N. S., \& Samaha, M. (2017). The relations among social media addiction, self-esteem, and life satisfaction in university students. Social Science Computer Review, 35, 576-586. https://doi.org/10.1177/0894439316660340

Hong, F. Y., Huang, D. H., Lin, H. Y., \& Chiu, S. L. (2014). Analysis of the psychological traits, Facebook usage, and Facebook addiction model of Taiwanese university students. Telematics and Informatics, 31, 597-606. https://doi.org/10.1016/j.tele.2014.01.001

Huang, H. (2014). Social media generation in urban China: A study of social media use and addiction among adolescents. Berlin: Springer.

Jelenchick, L. A., Eickhoff, J. C., \& Moreno, M. A. (2013). "Facebook depression?" Social networking site use and depression in older adolescents. Journal of Adolescent Health, 52, 128-130.

https://doi.org/10.1016/j.jadohealth.2012.05.008

Ji, Y. F., \& Yu, X. (1993). Self-esteem scale (SES). Manual of mental health rating scale. Chinese Journal of Mental Health, 251.

Jiang, T., Hou, Y., \& Wang, Q. (2016). Does micro-blogging make us "shallow"? Sharing information online interferes with information comprehension. Computers in Human Behavior, 59, 210-214.

https://doi.org/10.1016/j.chb.2016.02.008

Junco, R. (2012). The relationship between frequency of Facebook use, participation in Facebook activities, and student engagement. Computers \& Education, 58, 162-171. https://doi.org/10.1016/j.compedu.2011.08.004

Karpinski, A. C., Kirschner, P. A., Ozer, I., Mellott, J. A., \& Ochwo, P. (2013). An exploration of social networking site use, multitasking, and academic performance among United States and European university students.

Computers in Human Behavior, 29, 1182-1192. https://doi.org/10.1016/j.chb.2012.10.011

Kirschner, P. A., \& Karpinski, A. C. (2010). Facebook ${ }^{\circledR}$ and academic performance. Computers in Human Behavior, 26, 1237-1245. https://doi.org/10.1016/j.chb.2010.03.024 
Koc, M., \& Gulyagci, S. (2013). Facebook addiction among Turkish college students: The role of psychological health, demographic, and usage characteristics. Cyberpsychology, Behavior, and Social Networking, 16, 279-284. https://doi.org/10.1089/cyber.2012.0249

Kuss, D. J., \& Griffiths, M. D. (2011). Online social networking and addiction: A review of the psychological literature. International Journal of Environmental Research and Public Health, 8, 3528-3552.

https://doi.org/10.3390/ijerph8093528

Lane, J., Lane, A. M., \& Kyprianou, A. (2004). Self-efficacy, self-esteem and their impact on academic performance. Social Behavior and Personality, 32, 247-256. https://doi.org/10.2224/sbp.2004.32.3.247

LaRose, R., Lin, C. A., \& Eastin, M. S. (2003). Unregulated Internet usage: Addiction, habit, or deficient selfregulation? Media Psychology, 5, 225-253. https://doi.org/10.1207 /S1532785XMEP0503_01

Lau, W. W. (2017). Effects of social media usage and social media multitasking on the academic performance of university students. Computers in Human Behavior, 68, 286-291. https://doi.org/10.1016/j.chb.2016.11.043

Lent, R. W., Brown, S. D., \& Larkin, K. C. (1986). Self-efficacy in the prediction of academic performance and perceived career options. Journal of Counseling Psychology, 33, 265-269. https://doi.org/10.1037/0022-

0167.33.3.265

Li, H., \& Kam, W. B. (2002). Assessing psychological well-being of college student: Psychometric properties of GHQ-20. Psychological Development and Education, 1, 75-79. https://doi.org/10.16187/j.cnki.issn10014918.2002.01.016

Lin, C. Y., Broström, A., Nilsen, P., Griffiths, M. D., \& Pakpour, A. H. (2017). Psychometric validation of the Persian Bergen Social Media Addiction Scale using classic test theory and Rasch models. Journal of Behavioral Addictions, 6, 620-629. https://doi.org/10.1556/2006.6.2017.071

Lin, L. Y., Sidani, J. E., Shensa, A., Radovic, A., Miller, E., Colditz, J. B., \& Primack, B. A. (2016). Association between social media use and depression among US young adults. Depression and Anxiety, 33, 323-331.

https://doi.org/10.1002/da.22466

Liu, M., \& Peng, W. (2009). Cognitive and psychological predictors of the negative outcomes associated with playing MMOGs (massively multiplayer online games). Computers in Human Behavior, 25, 1306-1311.

https://doi.org/10.1016/j.chb.2009.06.002

Macan, T. H., Shahani, C., Dipboye, R. L., \& Phillips, A. P. (1990). College students' time management: Correlations with academic performance and stress. Journal of Educational Psychology, 82, 760-768.

https://doi.org/10.1037/0022-0663.82.4.760

Malik, S., \& Khan, M. (2015). Impact of Facebook addiction on narcissistic behavior and self-esteem among students. Journal of Pakistan Medical Association, 65, 260-263.

Marino, C., Finos, L., Vieno, A., Lenzi, M., \& Spada, M. M. (2017). Objective Facebook behaviour: Differences between problematic and non-problematic users. Computers in Human Behavior, 73, 541-546.

https://doi.org/10.1016/j.chb.2017.04.015

Marino, C., Gini, G., Vieno, A., \& Spada, M. M. (2018). A comprehensive meta-analysis on problematic Facebook use. Computers in Human Behavior, 83, 262-277. https://doi.org/10.1016/j.chb.2018.02.009

Mehdizadeh, S. (2010). Self-presentation 2.0: Narcissism and self-esteem on Facebook. Cyberpsychology, Behavior, and Social Networking, 13, 357-364. https://doi.org/10.1089/cyber.2009.0257 
Monacis, L., De Palo, V., Griffiths, M. D., \& Sinatra, M. (2017). Social networking addiction, attachment style, and validation of the Italian version of the Bergen Social Media Addiction Scale. Journal of Behavioral Addictions, 6 , 178-186. https://doi.org/10.1556/2006.6.2017.023

Nida, T. K. (2018). Facebook addiction and its association with academic performance. Biomedical Journal of Scientific \& Technical Research, 3(5), 1-3. https://doi.org/10.26717 /BJSTR.2018.03.000950

Ophir, E., Nass, C., \& Wagner, A. D. (2009). Cognitive control in media multitaskers. Proceedings of the National Academy of Sciences, 106, 15583-15587. https://doi.org/10.1073/pnas.0903620106

Orth, U., \& Robins, R. W. (2013). Understanding the link between low self-esteem and depression. Current Directions in Psychological Science, 22, 455-460. https://doi.org/10.1177/0963721413492763

Orth, U., Robins, R. W., \& Roberts, B. W. (2008). Low self-esteem prospectively predicts depression in adolescence and young adulthood. Journal of Personality and Social Psychology, 95, 695-708. https://doi.org/10.1037/00223514.95.3.695

Oulasvirta, A., \& Saariluoma, P. (2006). Surviving task interruptions: Investigating the implications of long-term working memory theory. International Journal of Human-Computer Studies, 64, 941-961.

https://doi.org/10.1016/j.ijhcs.2006.04.006

Pantic, I. (2014). Online social networking and mental health. Cyberpsychology, Behavior, and Social Networking, 17, 652-657. https://doi.org/10.1089/cyber.2014.0070

Pantic, I., Damjanovic, A., Todorovic, J., Topalovic, D., Bojovic-Jovic, D., Ristic, S., \& Pantic, S. (2012). Association between online social networking and depression in high school students: Behavioral physiology viewpoint. Psychiatria Danubina, 24, 90-93. https://doi.org/10.1002/mpr.1348

Pasek, J., \& Hargittai, E. (2009). Facebook and academic performance: Reconciling a media sensation with data. First Monday, 14. https://doi.org/10.5210/fm.v14i5.2498

Preacher, K. J., \& Hayes, A. F. (2008). Asymptotic and resampling strategies for assessing and comparing indirect effects in multiple mediator models. Behavior Research Methods, 40, 879-891.

https://doi.org/10.3758/BRM.40.3.879

Raskauskas, J., Rubiano, S., Offen, I., \& Wayland, A. K. (2015). Do social self-efficacy and self-esteem moderate the relationship between peer victimization and academic performance? Social Psychology of Education, 18, 297-314. https://doi.org/10.1007/s11218-015-9292-z

Rosenberg, M. (1965). Rosenberg self-esteem scale (RSE). Acceptance and commitment therapy. Measures Package, 61, 61-62.

Rosenberg, J., \& Egbert, N. (2011). Online impression management: Personality traits and concerns for secondary goals as predictors of self-presentation tactics on Facebook. Journal of Computer-Mediated Communication, 17, 118. https://doi.org/10.1111/j.1083-6101.2011.01560.x

Shakya, H. B., \& Christakis, N. A. (2017). Association of Facebook use with compromised well-being: A longitudinal study. American Journal of Epidemiology, 185, 203-211. https://doi.org/10.1093/aje/kww189

Shensa, A., Escobar-Viera, C. G., Sidani, J. E., Bowman, N. D., Marshal, M. P., \& Primack, B. A. (2017). Problematic social media use and depressive symptoms among US young adults: A nationally-representative study. Social Science \& Medicine, 182, 150-157. https://doi.org/10.1016/j.socscimed.2017.03.061 
Sowislo, J. F., \& Orth, U. (2013). Does low self-esteem predict depression and anxiety? A meta-analysis of longitudinal studies. Psychological Bulletin, 139, 213-240. https://doi.org/10.1037/a0028931

Spada, M. M., Langston, B., Nikčević, A. V., \& Moneta, G. B. (2008). The role of meta-cognitions in problematic internet use. Computers in Human Behavior, 24, 2325-2335. https://doi.org/10.1016/j.chb.2007.12.002

Starcevic, V. (2013). Is Internet addiction a useful concept? Australian and New Zealand Journal of Psychiatry, 47, 16-19. https://doi.org/10.1177/0004867412461693

Stone, C. B., \& Wang, Q. (2018). From conversations to digital communication: The mnemonic consequences of consuming and sharing information via social media. Topics in Cognitive Science, 2018, 1-20.

https://doi.org/10.1111/tops.12369

Tang, J. H., Chen, M. C., Yang, C. Y., Chung, T. Y., \& Lee, Y. A. (2016). Personality traits, interpersonal relationships, online social support, and Facebook addiction. Telematics and Informatics, 33, 102-108.

https://doi.org/10.1016/j.tele.2015.06.003

Toker, S., \& Baturay, M. H. (2016). Antecedents and consequences of game addiction. Computers in Human Behavior, 55, 668-679. https://doi.org/10.1016/j.chb.2015.10.002

Turel, O., Serenko, A., \& Giles, P. (2011). Integrating technology addiction and use: An empirical investigation of online auction users. Mis Quarterly, 35, 1043-1062. https://doi.org/10.2307/41409972

Uysal, R., Satici, S. A., \& Akin, A. (2013). Mediating effect of Facebook addiction on the relationship between subjective vitality and subjective happiness. Psychological Reports, 113, 948-953.

https://doi.org/10.2466/02.09.18.PR0.113×32z3

Valkenburg, P. M., Peter, J., \& Schouten, A. P. (2006). Friend networking sites and their relationship to adolescents' well-being and social self-esteem. CyberPsychology \& Behavior, 9, 584-590.

https://doi.org/10.1089/cpb.2006.9.584

van Rooij, A. J., Ferguson, C. J., van de Mheen, D., \& Schoenmakers, T. M. (2017). Time to abandon Internet addiction? Predicting problematic Internet, game, and social media use from psychosocial well-being and application use. Clinical Neuropsychiatry, 14, 113-121.

Vogel, E. A., Rose, J. P., Roberts, L. R., \& Eckles, K. (2014). Social comparison, social media, and selfesteem. Psychology of Popular Media Culture, 3, 206-222. https://doi.org/10.1037/ppm0000047

Wang, Q. (2013). The autobiographical self in time and culture. New York, NY: Oxford University Press.

Wen, Z., Hou, J., \& Zhang, L. (2005). A comparison of moderator and mediator and their applications. Acta Psychologica Sinica, 37, 268-274. https://doi.org/0439-755X(2005)37:2<268:TJXYYZ>2.0.TX;2-M

Wolniczak, I., Caceres-DelAguila, J. A., Palma-Ardiles, G., Arroyo, K. J., Solís-Visscher, R., Paredes-Yauri, S., \& Bernabe-Ortiz, A. (2013). Association between Facebook dependence and poor sleep quality: A study in a sample of undergraduate students in Peru. PLoS One, 8, e59087. https://doi.org/10.1371/journal.pone.0059087

Wood, E., Zivcakova, L., Gentile, P., Archer, K., De Pasquale, D., \& Nosko, A. (2011). Examining the impact of distracting multitasking with technology on real-time classroom learning. Computers \& Education, 58, 365-374. https://doi.org/10.1016/j.compedu.2011.08.029

Wu, A. M., Cheung, V. I., Ku, L., \& Hung, E. P. (2013). Psychological risk factors of addiction to social networking sites among Chinese smartphone users. Journal of Behavioral Addictions, 2, 160-166.

https://doi.org/10.1556/JBA.2.2013.006 
Yam, C. W., Pakpour, A. H., Griffiths, M. D., Yau, W. Y., Lo, C. L. M., Ng, J. M., . . Leung, H. (2018). Psychometric testing of three Chinese online-related addictive behavior instruments among Hong Kong university students. Psychiatric Quarterly, 2018, 1-12. https://doi.org/10.1007/s11126-018-9610-7

Young, K. S. (1999). Internet addiction: Symptoms, evaluation and treatment. In L. VandeCreek \& T. L. Jackson (Eds.), Innovations in clinical practice: A source book (Vol 17, pp. 19-31). Sarasota, FL: Professional Resource Press.

Young, K. S. (2007). Cognitive behavior therapy with Internet addicts: Treatment outcomes and implications. CyberPsychology \& Behavior, 10, 671-679. https://doi.org/10.1089/cpb.2007.9971

Zaremohzzabieh, Z., Samah, B. A., Omar, S. Z., Bolong, J., \& Kamarudin, N. A. (2014). Addictive Facebook use among university students. Asian Social Science, 10, 107. https://doi.org/10.5539/ass.v10n6p107

Zywica, J., \& Danowski, J. (2008). The faces of Facebookers: Investigating social enhancement and social compensation hypotheses: Predicting Facebook ${ }^{\mathrm{TM}}$ and offline popularity from sociability and self-esteem, and mapping the meanings of popularity with semantic networks. Journal of Computer-Mediated Communication, 14, 1-34. https://doi.org/10.1111/j.1083-6101.2008.01429.x

\section{Correspondence to:}

Yubo Hou

Beijing Key Laboratory of Behavior and Mental Health

5 Yiheyuan Rd

Beijing 100871

China

Email: houyubo(at)pku.edu.cn

$\&$

Qi Wang

Department of Human Development

Cornell University

Ithaca, NY 14853

USA

Email: qiwang(at)cornell.edu

Editorial record: First submission received on January 17, 2018. Revisions received on March, 6, 2018, October 10, 2018 and January 5, 2019. Accepted for publication on January 15, 2019. 


\section{About Authors}

Yubo Hou is an associate professor at Peking University's School of Psychological and Cognitive Sciences and Beijing Key Laboratory of Behavior and Mental Health, as well as a core member of the Center for Cultural Psychology at Tsinghua University. His major research interests include organizational behavior, personality and social psychology, social media, and cultural psychology. He is well-known for his cross-cultural research on the thinking styles of Chinese and Western populations. His current work focuses on behavioral problems and Confucian style of coping among Chinese adults, and the influence of social media on psychological wellbeing. Hou holds a BSc in Psychology from Zhejiang University and a Ph.D. in Social Psychology from Peking University.

Dan Xiong, Assistant Professor, Faculty of Psychology, Southwest University.

Tonglin Jiang, Ph.D candidate, Department of Psychology, The University of Hong Kong.

Lily Song, Ph.D candidate, Institute of Psychology, Chinese Academy of Science.

Qi Wang is a professor and department chair in Human Development at Cornell University. Her research integrates developmental, cognitive, and sociocultural perspectives to examine the mechanisms underlying the development of a variety of social-cognitive skills, including autobiographical memory, self, future thinking, and emotion knowledge. She has undertaken extensive studies to examine how cultural beliefs and goals influence social cognitive representations and processes by affecting information processing at the level of the individual and by shaping social practices between individuals. In addition, she has conducted studies to examine the impact of Internet technology as a cultural force unique to our time on cognitive functioning and well-being. A graduate of Peking University, China, Qi Wang earned a Ph.D. in psychology in 2000 at Harvard University. She has received many honors and awards and has over one hundred and fifty publications in scientific journals and in volumes of collected works. Her single-authored book, The Autobiographical Self in Time and Culture (2013, Oxford University Press), is regarded as the definitive work on culture and autobiographical memory. 